\title{
Invasion success of the seaweed Gracilaria vermiculophylla correlates with low palatibility
}

\author{
Mareike Hammann ${ }^{1, *}$, Gaoge Wang ${ }^{2}$, Esther Rickert $^{1}$, Sung Min Boo ${ }^{3}$, \\ Florian Weinberger ${ }^{1}$
}

\author{
${ }^{1}$ Helmholtz Centre for Ocean Research (GEOMAR), Düsternbrooker Weg 20, 24105 Kiel, Germany \\ ${ }^{2}$ College of Marine Life Sciences, Ocean University of China, 5 Yushan Road, 266003 Qingdao, China \\ ${ }^{3}$ Department of Biology, Chungnam National University, Daejeon 305-764, Korea
}

\begin{abstract}
Differences with respect to anti-herbivore defense were investigated in invasive and native populations of the seaweed Gracilaria vermiculophylla. Specimens from 6 native populations in East Asia and from 8 populations invasive in Europe and the Mexican Pacific coast were maintained under identical conditions and offered to herbivorous snails from both the native range (Littorina brevicula) and Europe (L. littorea) in no-choice feeding assays. L. brevicula consumed in total significantly larger amounts of $G$. vermiculophylla tissue than did L. littorea. Further, both snail species least consumed the seaweed specimens originating from either non-native populations or from populations native to the Korean East Sea/Sea of Japan. The Korean East Sea/Sea of Japan had previously been identified as putative donor region of all the invasive populations of G. vermiculophylla. Thus, populations in the donor region as well as non-native populations in different invaded realms feature an increased capacity to resist feeding pressure. Differences in nutrient content did not account for the observed patterns of consumption, as palatability and carbon to nitrogen $(\mathrm{C}: \mathrm{N})$ ratio were not significantly correlated. Thus, mechanical or chemical defenses or the content of feeding cues influenced the behavior of the snails. We suggest that low palatability contributed to the invasion success of the species.
\end{abstract}

KEY WORDS: Biological invasion - Invasive seaweeds · Enemy release hypothesis · Novel weapons hypothesis · Herbivory · Gracilaria vermiculophylla

\section{INTRODUCTION}

For terrestrial plants and also for seaweeds (Nyberg \& Wallentinus 2005), grazing defense is thought to be an important biological trait that determines invasiveness. High levels of novel phytochemicals (so called 'novel weapons') that native plants, grazers, or pathogens have not previously encountered have often been predicted to favor introduced plants in new environments (Callaway \& Ridenour 2004, Cappuccino \& Carpenter 2005, Cappuccino \& Arnason 2006, Forslund et al. 2010). Correspondingly, pres- ence of generalist enemies in new environments might result in a selection of defensive traits in introduced plants (Blossey \& Notzold 1995, Callaway \& Ridenour 2004). In contrast, the 'enemy release' hypothesis (Keane \& Crawley 2002) attributes the success of introduced plants to a lack of specialist enemies in the invaders' new ranges. Under such conditions, invasive plants might lose their protection against specialist herbivores, allowing a shift towards higher protection against generalist herbivores (Joshi \& Vrieling 2005). However, in contrast to terrestrial plants, introduced seaweeds are often not 
released from grazers, as significantly more herbivores in the sea than on land are generalists (Hay \& Steinberg 1992).

Several studies have quantified grazing on invasive seaweed species in their new range, and in most cases, grazers from the introduced range preferred native over non-native seaweeds (Weinberger et al. 2008, Monteiro et al. 2009, Cacabelos et al. 2010, Engelen et al. 2011, Nejrup et al. 2012). This low feeding pressure could explain the invasiveness of non-native algae. However, all those studies were conducted only in the invader's introduced range. Hierro et al. (2005) state the importance of studying exotic species not only in their introduced ranges, as there is a gap in knowledge about the ecology of these species in their native habitats. For testing herbivory-related invasion hypotheses, comparisons of the effects of grazers in the native and the introduced range are therefore crucial. Wikström et al. (2006) were the first to compare native and nonnative populations of a seaweed species with regard to feeding pressure and grazing defense, instead of comparing invasive and co-occurring native species. Their study revealed that the rockweed Fucus evanescens is less exposed to herbivory in its non-native range in Sweden than in its native range in Iceland, probably due to an increased chemical defense in invasive populations. Both Iceland and Sweden belong to the same Northern European coastal ecoprovince, and the inventories of seaweed-consuming species that are present in these regions show considerable overlap (Spalding et al. 2007). Introduction into new ecoprovinces or even realms might confront the invader with more drastic changes in interspecific interactions. Our aim was therefore to expand the comparison of invasive and non-invasive macroalgal populations over a larger geographical scale, in order to cover environments with more divergent species inventories.

The red macroalga Gracilaria vermiculophylla (Ohmi) Papenfuss was chosen as a model organism, as its large tolerance towards environmental stress (Yokoya et al. 1999, Thomsen \& McGlathery 2007, Weinberger et al. 2008, Nyberg \& Wallentinus 2009) makes it suitable for common garden-like experiments that require long-distance transportation under suboptimal conditions. The native distribution range of the species is in the cold and warm temperate Northwest Pacific ecoprovinces, ranging from the Northern Sea of Japan to the East China Sea and the Central Kuroshio Current. During the last 2 decades, G. vermiculophylla has not only spread to the cold (Saunders 2009) and warm (Bellorin et al. 2004) tem- perate North American west coasts, but also to most ecoprovinces of the temperate Northern Atlantic realm: cold (Saunders 2009) and warm (Freshwater et al. 2006) temperate North American east coasts, Mediterranean Sea (Sfriso et al. 2010), Lusitanian coasts (Guillemin et al. 2008), and Northern European seas, including the Baltic Sea (Schories \& Selig 2006, Nyberg 2007, Thomsen et al. 2007a,b, Weinberger et al. 2008). G. vermiculophylla spreads rapidly, tends to change the flora and fauna of invaded habitats, and has been included among the most invasive seaweeds in Europe (Nyberg 2007). The invasion process has resulted in a considerable loss of genetic diversity in non-native populations of G. vermiculophylla, all of which seem to have a common genetic origin in a donor region within the Korean East Sea/Sea of Japan (Kim et al. 2010).

Local mass appearances and ecological dominance of Gracilaria vermiculophylla have repeatedly been observed in areas outside of its native range (Freshwater et al. 2006, Thomsen et al. 2006, 2007a, PinonGimate et al. 2008, Weinberger et al. 2008). To our knowledge, mass appearances have not been reported for native populations of G. vermiculophylla. This discrepancy could result from many possible reasons. A more stringent control by native than by nonnative feeding enemies is one of them, as G. vermiculophylla from non-native populations seems to be less affected by herbivores than native seaweeds from the same environment (Weinberger et al. 2008, Nejrup et al. 2012).

Unlike terrestrial plants, many algae only have a low proportion of structural material that could act as a morphological defense against grazers. Therefore they rely on other defense mechanisms, such as the use of chemical feeding deterrents (Hay \& Steinberg 1992). Also, Gracilaria vermiculophylla is capable of defending itself from herbivory by mesograzers: if tissue is damaged - either by artificial mechanical wounding or by grazing - the alga produces oxylipins (Nylund et al. 2011, Rempt et al. 2012). These compounds deter potential grazers of G. vermiculophylla, such as the omnivorous isopod Idotea balthica (Nylund et al. 2011) or the herbivorous sea snail Echinolittorina peruviana (Rempt et al. 2012). Wound-activated oxylipins are also molecular messengers that mediate induced defenses of gracilarioids (Weinberger et al. 2011).

The consumption of Gracilaria vermiculophylla by certain mesograzers may therefore be reduced due to chemical defenses of the alga. On the other hand, herbivores depend on the ingestion of plant-derived nitrogen and are therefore assumed to prefer plants 
with a high proportion of nitrogen, thus with a low carbon to nitrogen (C:N) ratio (Mattson 1980). In accordance with this, Littorina littorea consumed and retained more food in nutrient-enriched environments and gained a higher biomass (Diaz et al. 2012). Likewise, feeding preferences of the snail L. sitkeana among different seaweeds were primarily determined by the C:N ratio (Van Alstyne et al. 2009), and the amphipod Gammarus locusta actively chose high-quality nutrient-rich food as well (Kraufvelin et al. 2006).

The main hypotheses tested in the present study were the following: (1) Gracilaria vermiculophylla is less palatable to grazers from the invaded range as compared to grazers from the native range because invader and grazers in the new habitat do not share a co-evolutionary history (as predicted by the enemy release hypothesis), (2) G. vermiculophylla originating from non-native populations is in general less palatable than $G$. vermiculophylla from native populations because it has evolved resistance against herbivores during the invasion process (as predicted by the novel weapons hypothesis), and (3) a disposition to relatively low palatability of $G$. vermiculophylla populations from the Korean East Sea/Sea of Japan has facilitated the invasion success of specimens from this donor region (through selection of preadapted genotypes).

To test these hypotheses, Gracilaria vermiculophylla from 6 native and 8 invasive populations was fed in no-choice feeding experiments of commongarden type to (1) the snail Littorina brevicula Philippi, which has a similar distribution range in East Asia as G. vermiculophylla (Son \& Hong 1998,
Kim et al. 2003), and (2) L. littorea L., a common grazer in most of the regions invaded by $G$. vermiculophylla in the North Atlantic realm. L. littorea is able to feed on a variety of macroalgae (Watson \& Norton 1985, Diaz et al. 2012), and its Asian conspecific is a generalist herbivore as well (Molis et al. 2008). Feeding experiments with $L$. brevicula were conducted in Qingdao, China, and feeding assays with L. littorea were carried out in Kiel, Germany. C:N ratios of G. vermiculophylla specimens offered in feeding assays were analyzed in order to investigate whether differences in nutrient content explained differences in palatability. The combination of several native and non-native seaweed populations with congeneric grazers of either the native or the introduced range in a common garden was a new approach in the frame of testing herbivory-related invasion theories in marine ecology. Furthermore, it also ensured that the detected effects were not only due to local adaptation (Williams et al. 2008).

\section{MATERIALS AND METHODS}

\section{Collection, transport, and cultivation of Gracilaria vermiculophylla}

Between 10 February and 22 April 2010, 6 native populations of Gracilaria vermiculophylla were sampled along the Korean peninsula and in Shandong Province, China, and 8 non-native populations were sampled around the Danish-German peninsula of Jutland and Schleswig-Holstein, in the west of France, and on the Pacific coast of Mexico (Table 1).

Table 1. Gracilaria vermiculophylla. Geographic location and taxonomic reference (GenBank accession numbers are given for new cox1 gene sequences generated in the framework of the present study) of native and non-native populations

\begin{tabular}{|c|c|c|c|}
\hline & Population/abbreviation (sea area) & Geographic coordinates & $\begin{array}{l}\text { Taxonomic } \\
\text { reference }\end{array}$ \\
\hline \multirow[t]{6}{*}{ Native } & Donghae/Dong (East Sea, South Korea) & $37^{\circ} 29^{\prime} 27.65^{\prime \prime} \mathrm{N}, 129^{\circ} 08^{\prime} 30.42^{\prime \prime} \mathrm{E}$ & JQ736332 \\
\hline & Odo-ri/Odo (East Sea, South Korea) & $36^{\circ} 09^{\prime} 52.40^{\prime \prime} \mathrm{N}, 129^{\circ} 24^{\prime} 00.07^{\prime \prime} \mathrm{E}$ & JQ736333 \\
\hline & Jindo/Jin (Yellow Sea, South Korea) & $34^{\circ} 25^{\prime} 16.98^{\prime \prime} \mathrm{N}, 126^{\circ} 20^{\prime} 48.21^{\prime \prime} \mathrm{E}$ & Kim et al. (2010) \\
\hline & Gyeokpo/Gye (Yellow Sea, South Korea) & $35^{\circ} 37^{\prime} 05.54^{\prime \prime} \mathrm{N}, 126^{\circ} 28^{\prime} 01.70^{\prime \prime} \mathrm{E}$ & Kim et al. (2010) \\
\hline & Daecheon/Dae (Yellow Sea, South Korea) & $36^{\circ} 19^{\prime} 23.07^{\prime \prime} \mathrm{N}, 126^{\circ} 30^{\prime} 07.81^{\prime \prime} \mathrm{E}$ & Kim et al. (2010) \\
\hline & Qingdao/Qing (Yellow Sea, China) & $36^{\circ} 03^{\prime} 18.51^{\prime \prime} \mathrm{N}, 120^{\circ} 21^{\prime} 57.01^{\prime \prime} \mathrm{E}$ & Kim et al. (2010) \\
\hline \multirow[t]{8}{*}{ Non-native } & Heiligenhafen/Hhafen (Baltic Sea, Germany) & $54^{\circ} 22^{\prime} 48.14^{\prime \prime} \mathrm{N}, 10^{\circ} 58^{\prime} 58.94^{\prime \prime} \mathrm{E}$ & JQ736335 \\
\hline & Nyborg/Ny (Baltic Sea, Denmark) & $55^{\circ} 17^{\prime} 54.23^{\prime \prime} \mathrm{N}, 10^{\circ} 49^{\prime} 07.35^{\prime \prime} \mathrm{E}$ & JQ736339 \\
\hline & Horsens/Hor (Baltic Sea, Denmark) & $55^{\circ} 51^{\prime} 35.02^{\prime \prime} \mathrm{N}, 9^{\circ} 52^{\prime} 35.76^{\prime \prime} \mathrm{E}$ & KC731475 \\
\hline & Nibe/Nibe (Limfjord, Denmark) & $56^{\circ} 59^{\prime} 03.34^{\prime \prime} \mathrm{N}, 9^{\circ} 37^{\prime} 48.89^{\prime \prime} \mathrm{E}$ & JQ736338 \\
\hline & Mandö/Man (Wadden Sea, Denmark) & $55^{\circ} 18^{\prime} 35.59^{\prime \prime} \mathrm{N}, 8^{\circ} 38^{\prime} 34.74^{\prime \prime} \mathrm{E}$ & JQ736337 \\
\hline & Nordstrand/Nord (Wadden Sea, Germany) & $54^{\circ} 31^{\prime} 48.01^{\prime \prime} \mathrm{N}, 8^{\circ} 52^{\prime} 18.88^{\prime \prime} \mathrm{E}$ & JQ736336 \\
\hline & St.-Pol-de-Leon/St.-Pol (Brittany, France) & $48^{\circ} 40^{\prime} 41.09^{\prime \prime} \mathrm{N}, 3^{\circ} 58^{\prime} 08.04^{\prime \prime} \mathrm{W}$ & Kim et al. (2010) \\
\hline & Ensenada/Ens (Baja California, Mexico) & $31^{\circ} 46^{\prime} 28.67^{\prime \prime} \mathrm{N}, 116^{\circ} 36^{\prime} 40.92^{\prime \prime} \mathrm{W}$ & JQ736334 \\
\hline
\end{tabular}


The identity of all studied populations was confirmed by DNA barcoding, either by Kim et al. (2010) or by us, using the methodology described in Kim et al. (2010) (Table 1). G. vermiculophylla individuals from native populations were easily distinguishable, as each plant was growing attached to hard substratum. However, G. vermiculophylla from non-native populations was often growing unattached, and so it cannot be ruled out that some of the used 'individuals' were in fact clonal, although both native and nonnative plants were sampled in extended areas of $>1000 \mathrm{~m}^{2}$ to avoid taking clonal samples.

For the feeding experiments with Littorina brevicula and L. littorea, specimens from all Gracilaria vermiculophylla populations were transferred alive to both Qingdao (China) and Kiel (Germany), respectively. They were transported wrapped into seawater-wetted lab paper and in cooling containers (Nyberg \& Wallentinus 2009). In order to exert as little stress as possible, transportation periods never exceeded $5 \mathrm{~d}$, and for logistic reasons the transportation between collection site and experimental site could not always be direct. Specimens originating from native populations were transported directly to Qingdao and Kiel, while specimens originating from non-native populations were brought to Kiel first. After a regeneration period where they were kept under non-stressful conditions for at least $2 \mathrm{wk}$, one half was transported to Qingdao, while the other half remained in Kiel. Losses due to transportation stress were not observed. After transportation and prior to feeding assays, all specimens were kept under nonstressful conditions for at least $1 \mathrm{wk}$ before conducting the feeding assays to allow for regeneration. In Qingdao, they were for this purpose cultivated in separate Erlenmeyer flasks at identical conditions (room temperature, i.e. approx. $20^{\circ} \mathrm{C}$ indirect sunlight, i.e. maximum photosynthetically active radia-

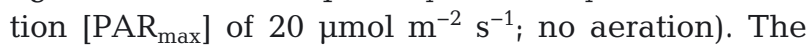
medium (Yellow Sea water) was exchanged daily. At Kiel, the cultivation for regeneration took place in separate indoor tanks under identical conditions (water temperature: 15 to $20^{\circ} \mathrm{C}_{i}$ PAR: $30 \mu \mathrm{mol} \mathrm{m}^{-2} \mathrm{~s}^{-1}$ for $16 \mathrm{~h} \mathrm{~d}^{-1}$; aeration). The medium was Baltic Sea water from the Kiel Fjord. It was constantly exchanged between all tanks and a central storage container, in order to maintain an identical composition in all tanks. At the exit of the central container and prior to redistribution into the tanks, the water was UV-sterilized, in order to prevent exchange of algal propagules among tanks containing material of different origin. For experiments conducted in Qingdao, seaweeds that were sampled at low salinity condi- tions (Baltic Sea) were slowly (stepwise over several days) acclimatized to fully marine conditions, while seaweeds from fully marine conditions were slowly adapted to low salinity conditions (salinity: $15 \pm 2$ ) before using them for experiments in Kiel.

\section{Collection of Littorina brevicula and L. littorea}

Three days before the feeding experiment started, Littorina brevicula individuals were collected on the Yellow Sea coast in Qingdao (36 03' 18.51" N, $\left.120^{\circ} 21^{\prime} 57.01^{\prime \prime} \mathrm{E}\right)$ at a site where Gracilaria vermiculophylla was present. Snails were maintained in the laboratory in an aquarium containing $5 \mathrm{l}$ of Yellow Sea water (salinity: 33), which was exchanged twice every day. During this period they were allowed to graze on green algae (Ulva sp.). The diameter of the snails was measured prior to the experiment. Snails with a diameter between 7 and $9 \mathrm{~mm}$ were most common in the habitat at the time of sampling (April) and were therefore used for experiments.

Littorina littorea individuals were collected on the shore of the Kiel Fjord ( $\left.54^{\circ} 21.965^{\prime} \mathrm{N}, 10^{\circ} 8.908^{\prime} \mathrm{E}\right)$ at a site where Gracilaria vermiculophylla was present. They were kept in a flow-through aquarium containing 51 of Baltic Sea water (salinity: $15 \pm 2$ ) prior to the bioassay. During this period of $3 \mathrm{~d}$, they were allowed to graze on green algae (Ulva sp.). For this experiment, snails with a diameter between 8 and $12 \mathrm{~mm}$ were used.

\section{Feeding assays}

The experiments with Littorina brevicula were conducted in April 2010 and experiments with L. littorea in May 2010. For the no-choice feeding assays, 10 algal individuals per Gracilaria vermiculophylla population were used. Each of the 10 replicates was cut in 2 pieces of $0.1 \pm 0.005 \mathrm{~g}$ (blotted wet weight): One was exposed to snails and the second one was used as control of autogenic changes during the course of the experiment. At Qingdao, all algal pieces were incubated in Petri dishes (diameter: $9 \mathrm{~cm}$ ) containing water from the Yellow Sea (salinity: 33), which was exchanged every day. The experiment lasted for $7 \mathrm{~d}$, and 4 snails were used in each treatment. At Kiel, the experimental setup was identical, with 3 exceptions: the water originated from the Kiel Fjord (salinity: $15 \pm 2$ ), and only 3 snails were used per Petri dish, as they were larger than those at Qingdao. Also, L. littorea individuals were allowed to 
consume the algae for $12 \mathrm{~d}$, as the feeding rates were generally lower than for $L$. brevicula. Experiments were run in a constant temperature room $\left(16^{\circ} \mathrm{C}\right)$ in Kiel. In Qingdao, those facilities were not available, but temperatures were in the same range (15 to $20^{\circ} \mathrm{C}$ ).

At the end of each experiment, algae exposed and unexposed to snails were weighed again and net growth was determined. To get comparable growth data for both experiments, the daily weight change of Gracilaria vermiculophylla was determined and related to the respective soft body dry weight (DW) of the snails. Soft body DW was ascertained from shell diameters of the 2 snail species as follows. The diameter of snails of different sizes was measured (Littorina brevicula: $\mathrm{n}=46$, diameter: 4 to $10 \mathrm{~mm}$; L. littorea: $\mathrm{n}=61$, diameter: 6 to $15 \mathrm{~mm}$ ). The soft body was removed from the shell and dried at $50^{\circ} \mathrm{C}$ until weight constancy. Regressions were then calculated between shell diameters and soft body DW of both species, so that the soft body DW of the snails in each Petri dish could be assessed.

\section{C:N analysis}

Remains of every Gracilaria vermiculophylla individual used in the feeding assays were conserved in silica gel for C:N analysis. From both series of experiments, 5 randomly selected replicates per population were analyzed. The dried algal pieces were ground in a mixer mill (Retsch), and C:N ratios were determined in a Euro Vector EA 3000 Elemental Analyzer (Eurovector).

\section{Statistical analysis}

Prior to statistical tests, consumption data and C:N ratios were Box-Cox-transformed to achieve homogeneity of variances and normality. Homogeneity of variances could not be achieved for all factors (Levine's test, $\mathrm{p}<0.05$ ), and in these cases, results were taken in the following tests as statistically significant if the probability of error was $<1 \%$ (Underwood 1997), while other results were taken as statistically significant at a p-level of $5 \%$. Differences in consumption rates of either Littorina brevicula or L. littorea were analyzed by nested-design ANOVA, with the factor 'population' nested within the factor 'region' (native or non-native). Differences among single populations were detected with Tukey's post hoc test. A linear regression was fitted between con- sumption rates of $L$. brevicula and L. littorea, in order to find out if both snail species preferably fed on the same populations of Gracilaria vermiculophylla. Linear regression was also used to detect correlations among $\mathrm{C}: \mathrm{N}$ ratios and feeding patterns. Box-Cox transformations and statistical tests were conducted using the STATISTICA 8 software package (StatSoft), while regressions were fitted using GraphPad Prism 4 software.

\section{RESULTS}

Both Littorina brevicula and L. littorea found Gracilaria vermiculophylla individuals originating from native populations more palatable, and consumed $>3$ times as much of them compared to specimens originating from invasive populations $(\mathrm{p}<0.001$; Fig. 1, Table 2).

Interestingly, there was a high variability within the native populations, and the origin of native specimens influenced consumption rates of Littorina brevicula significantly ( $p<0.001$; Fig. 2 A, Table 2 ). Seaweeds from Jindo (South Korea) were consumed more than all other native populations, except for those from Qingdao (China) and Gyeokpo (South Korea). Populations from Daecheon, Odo, and Donghae (South Korea) were consumed significantly less than the seaweed individuals from Jindo, and had an average $\left( \pm\right.$ SE) biomass loss of $14.7 \pm 2.9 \mathrm{mg} \mathrm{d}^{-1}$ (g DW L. brevicula $)^{-1}$. Variability within the invasive

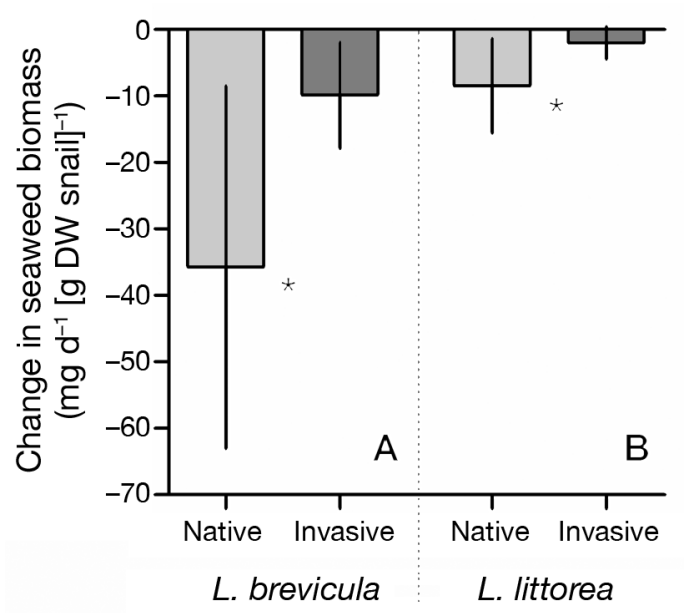

Fig. 1. Gracilaria vermiculophylla, Littorina brevicula, and L. littorea. Average biomass loss of G. vermiculophylla from native and invasive populations caused by consumption by (A) L. brevicula and (B) L. littorea in feeding experiments. ${ }^{*}$ Native and invasive populations significantly different in a nested 2-way ANOVA (see factor 'region' in Table 2; p < 0.001). $\mathrm{n}=7$ to 10 . Whiskers: $\pm 95 \% \mathrm{CI}$ 
Table 2. Gracilaria vermiculophylla, Littorina brevicula, and L. littorea. Influence of the origin of $G$. vermiculophylla populations on the biomass consumed by $L$. brevicula and $L$. littorea in feeding experiments, using a nested-design ANOVA with the factor 'population' nested within the factor 'region' (either native or invasive)

\begin{tabular}{|lcrcrc|}
\hline & SS & df & MS & \multicolumn{1}{c|}{$F$} & p \\
\hline L. brevicula & & & & & \\
Population (Region) & $4.50 \times 10^{10}$ & 12 & $3.75 \times 10^{9}$ & 4.41 & $<0.001$ \\
Region & $3.02 \times 10^{10}$ & 1 & $3.02 \times 10^{10}$ & 35.56 & $<0.001$ \\
Error & $1.04 \times 10^{11}$ & 122 & $8.50 \times 10^{8}$ & & \\
L. littorea & & & & & \\
Population (Region) & $3.34 \times 10^{8}$ & 12 & $2.78 \times 10^{7}$ & 4.34 & $<0.001$ \\
Region & $1.37 \times 10^{8}$ & 1 & $1.37 \times 10^{8}$ & 21.46 & $<0.001$ \\
Error & $7.24 \times 10^{8}$ & 113 & $6.41 \times 10^{6}$ & & \\
\hline
\end{tabular}

Average $( \pm \mathrm{SE})$ biomass loss of invasive populations was $10.2 \pm 2.5 \mathrm{mg} \mathrm{d}^{-1}$ (g DW L. brevicula) ${ }^{-1}$, and thus similar to populations from Daecheon, Odo, and Donghae.

Consumption of Littorina littorea also varied significantly within native populations, but not within invasive populations $(p<0.001$; Fig. $2 B$, Table 2). Specimens from Jindo (South Korea) and Qingdao (China) were consumed significantly more than algae from other native populations, with the exception of those from Gyeokpo (South Korea) and Odo (South Korea). Material from Daecheon and Donghae (South Korea; biomass loss $[ \pm \mathrm{SE}]: 1.9 \pm 2.4$ and $1.1 \pm 0.4 \mathrm{mg} \mathrm{d}^{-1}$ [g DW L. littorea $]^{-1}$, respectively) was consumed significantly less than specimens from Jindo and Qingdao, and showed consumption rates in a similar range as Gracilaria vermiculophylla from invasive populations (average $\left[ \pm \mathrm{SE}\right.$ ] biomass loss: $2.0 \pm 0.5 \mathrm{mg} \mathrm{d}^{-1}$ [g DW L. littorea] ${ }^{-1}$ ).

Littorina brevicula and L. littorea tended to find the same populations of Gracilaria vermiculophylla most palatable (Fig. 3). Two of the native populations (Jindo from South Korea, and Qingdao from China) were consumed most by both herbivores, while the consumption of 2 other native populations (Daecheon and Donghae, South Korea) was similar to that of invasive populations. Seaweeds from Gyeokpo (South Korea) were in both experiments consumed at an intermediate range. Seaweeds from Odo (South Korea), however, differed between experiments in

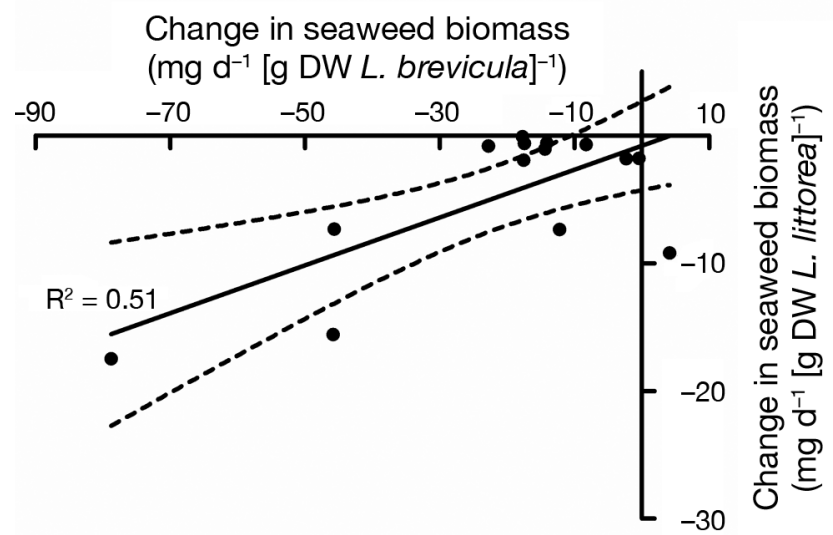

Fig. 3. Gracilaria vermiculophylla, Littorina brevicula, and L. littorea. Linear regression correlating the biomass of G. vermiculophylla per population consumed by $L$. brevicula and L. littorea. Dotted lines: $95 \%$ CI tions, and Tukey's post hoc test did not detect any significant differences between them (see Fig. 2A).
Fig. 2. Gracilaria vermiculophylla, Littorina brevicula, and L. littorea. Consumption of biomass of different G. vermiculophylla populations by (A) L. brevicula and (B) L. littorea in feeding experiments. Different letters indicate populations that were significantly different in a Tukey test $(\mathrm{p}<$ $0.01)$ either within the native or within the non-native region. $\mathrm{n}=7$ to 10 . Whiskers: $\pm 95 \%$ CI. See Table 1 for population abbreviations

populations was lower than within native popula- 
the native and the invaded rangewhile they were not much consumed by $L$. brevicula, the consumption by $L$. littorea was at an intermediate level.

However, the total amounts consumed were significantly higher for Littorina brevicula, which fed more than 5-fold the amount of Gracilaria vermiculophylla compared to $L$. littorea (Fig. 1). The difference becomes even more distinct when the combinations of snails and seaweeds existing in nature ( $L$. brevicula and G. vermiculophylla from Qingdao and L. littorea and G. vermiculophylla from the German Baltic coast) are compared - $L$. brevicula consumed 90 -fold the amount consumed by L. littorea.

At the end of both experiments, the $\mathrm{C}: \mathrm{N}$ ratios differed between native and invasive populations of Gracilaria vermiculophylla ( $\mathrm{p}<0.001$; Fig. 4, Table 3), with slightly higher relative nitrogen contents in the invasive species. Significant differences in $\mathrm{C}: \mathrm{N}$ ratios were also detected among single populations (experiment in Qingdao: $\mathrm{p}<0.001$; Fig. 5A, Table 3; experiment in Kiel: $p<0.01$; Fig. 5B, Table 3). However, there was no obvious distribution pattern among native or invasive algae, and the variability was high.

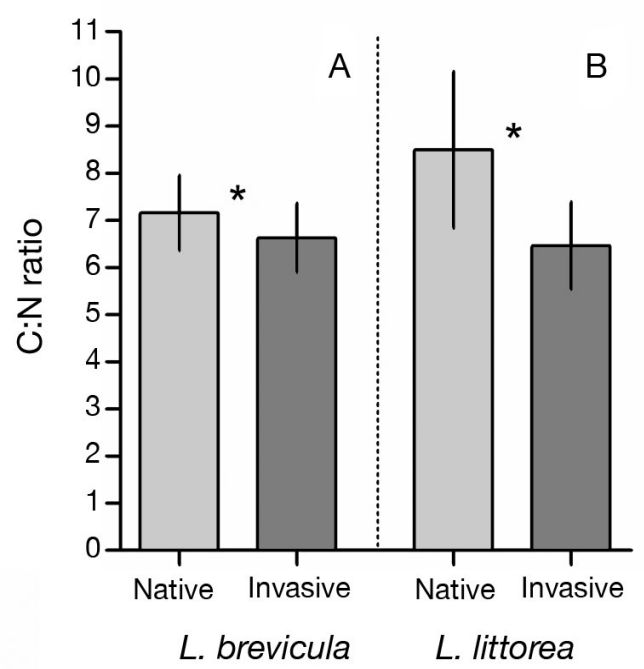

Fig. 4. Gracilaria vermiculophylla, Littorina brevicula, and $L$. littorea. Means of $\mathrm{C}: \mathrm{N}$ ratios for native and invasive G. vermiculophylla populations consumed by (A) L. brevicula and (B) L. littorea. *Native and invasive populations significantly different in a nested 2-way ANOVA (see factor 'region' in Table 3; $\mathrm{p}<0.001$ ). $\mathrm{n}=5$. Whiskers: $\pm 95 \% \mathrm{CI}$
We detected no significant correlations between $\mathrm{C}: \mathrm{N}$ ratios and biomass consumption by Littorina brevicula or L. littorea (Fig. 6).

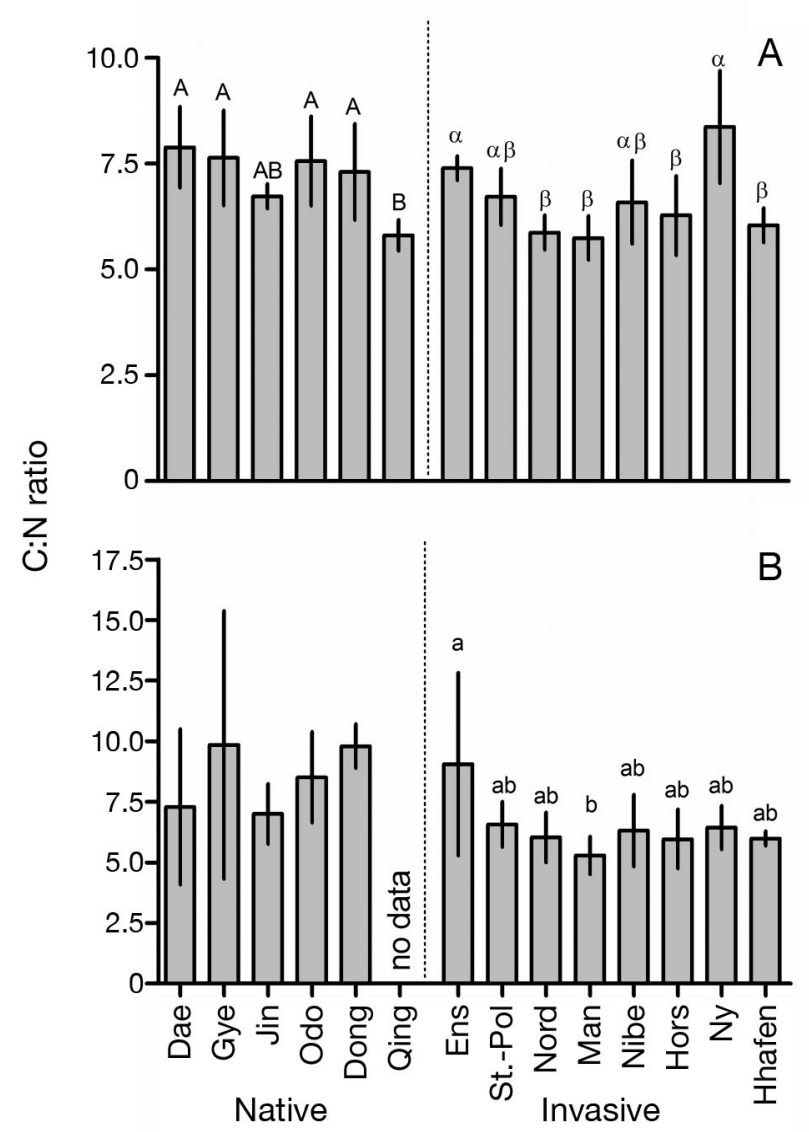

Fig. 5. Gracilaria vermiculophylla, Littorina brevicula, and L. littorea. Averages of C:N ratios for single G. vermiculophylla populations consumed by (A) L. brevicula and (B) L. littorea. Different letters indicate populations that were significantly different in a Tukey test $(p<0.01)$ either within the native or within the non-native region. $n=5$. Whiskers: $95 \%$ CI. See Table 1 for population abbreviations 


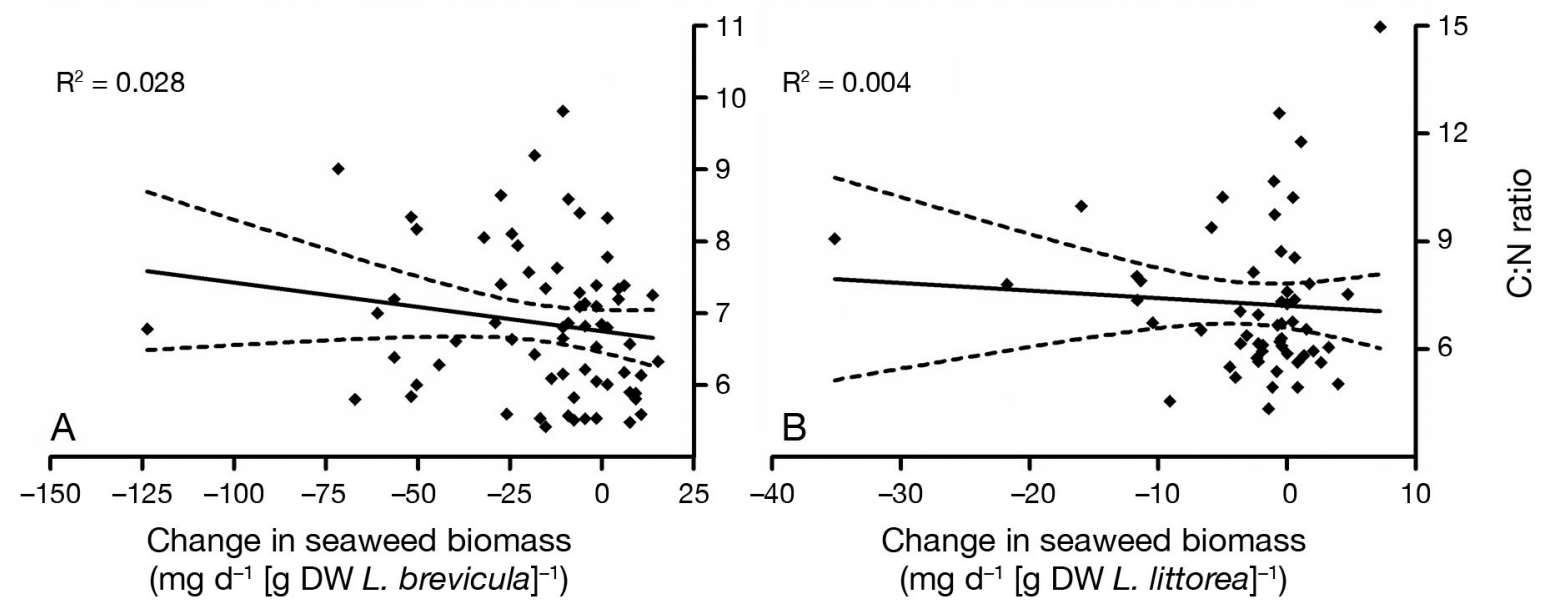

Fig. 6. Gracilaria vermiculophylla, Littorina brevicula, and L. littorea. Linear regression of C:N ratios of G. vermiculophylla biomass and biomass consumed by (A) L. brevicula and (B) L. littorea. Dotted lines indicate $95 \%$ CI

\section{DISCUSSION}

The employment of both native and non-native populations of Gracilaria vermiculophylla in combination with congeneric generalist herbivores from the native range (Littorina brevicula) and the invaded range (L. littorea) allows us to answer several questions: Are non-native populations of the seaweed in general more sensitive to grazing than native populations? Do feeding rates differ among single populations? Do $L$. brevicula and L. littorea consume similar amounts of the seaweed or is G. vermiculophylla less palatable to the grazer in the new range? The comparison between the consumption rates of the 2 snail species has to be looked at with some caution, as conditions at the experimental sites were similar, but not identical. It is possible that $L$. brevicula has in general higher consumption rates than L. littorea or that it coped better with the laboratory conditions. However, the behavior of all snails seemed normal, and losses during the experimental period were not observed. Light and temperature regimes were in a similar range, but the salinity differed, as we used the salinity conditions that were present at the respective sampling sites of the snails to avoid stress. Nevertheless, the differences are quite remarkable: $L$. brevicula from the native range consumed in total significantly higher amounts $( \pm \mathrm{SE})$ of algal tissue $\left(21.4 \pm 2.8 \mathrm{mg} \mathrm{d}^{-1} \mathrm{~g}^{-1}\right.$ when averaged over all algal populations) than the phylogenetically related $L$. littorea from the non-native range $\left(4.3 \pm 0.8 \mathrm{mg} \mathrm{d}^{-1} \mathrm{~g}^{-1}\right)$. The ratio was 90 -fold when naturally occurring matches of seaweed and herbivore in Qingdao (China) and in the German Baltic were compared. At
Qingdao, G. vermiculophylla inhabits the upper eulittoral close to the supralittoral fringe. $L$. brevicula is the main character species of this habitat (Morton 1990), and the alga is frequently subject to consumption by the snail (authors' pers. obs.). In the atidal Baltic Sea at Kiel and Heiligenhafen, both L. littorea and $G$. vermiculophylla inhabit the upper sublittoral, and the snail is 1 of the 2 main feeding antagonists, together with the isopod Idotea baltica (Weinberger et al. 2008). However, both consumers preferably feed on the native brown seaweed Fucus vesiculosus rather than on $G$. vermiculophylla when both are offered in 2-way-choice experiments (Weinberger et al. 2008). Nejrup \& Pedersen (2010) examined in situ grazing losses of non-native G. vermiculophylla in Denmark over an entire growth season, but did not find significant losses due to grazing. The feeding pressure on native populations of $G$. vermiculophylla in the field has not been determined yet. However, on the Chinese and South Korean coasts, L. brevicula can occur in markedly high numbers, while densities of L. littorea on the German and Danish coasts seem to be lower (authors' pers. obs.). At the same time, our experiments indicate that the grazer $L$. littorea from the invaded range is less attracted or more deterred by the metabolic composition of G. vermiculophylla than the snail from the native range.

It was most obvious that both snail species preferred to feed on the native seaweeds. Both Littorina littorea and $L$. brevicula consumed more than 3 times larger amounts of native than of invasive Gracilaria vermiculophylla. Apparently, G. vermiculophylla originating from the invaded range was less palatable. Consequently, the question should be asked whether 
differences in $\mathrm{C}: \mathrm{N}$ ratios could be responsible for the observed differences in consumption of the algal material. Similarly to the differences in consumption, $\mathrm{C}: \mathrm{N}$ ratios also differed significantly among native and invasive algal specimens. Slightly higher C:N ratios were detected in native individuals. However, snails of the genus Littorina have been attracted to food with low rather than high C:N ratios (Van Alstyne et al. 2009). Moreover, there were no significant correlations between $\mathrm{C}: \mathrm{N}$ ratios and biomass consumption by L. brevicula or L. littorea. The C:N contents of the seaweeds can therefore not explain the observed feeding patterns. In this light, it seems more likely that the snails were influenced by specific deterrents or feeding cues. G. vermiculophylla is able to defend itself from feeding by up-regulation of chemical compounds. After wounding, the alga produces - among other substances - arachidonic acid derivates, which were found to deter mesograzers such as the omnivorous isopod Idotea baltica (Nylund et al. 2011) or the herbivorous sea snail Echinolittorina peruviana (Rempt et al. 2012). It seems likely that these or other substances also act as feeding deterrents against $L$. brevicula and $L$. littorea. In a study with the invasive red alga Bonnemaisonia hamifera, Enge et al. (2012) were able to show that low consumption in the new range of the seaweed can be directly attributed to a specific chemical defense against native generalists that did not encounter this type of chemical defense before. They conclude that novel chemical weapons against naive herbivores might provide a mechanistic explanation for algal invasion success. The lower palatability of non-native populations of $G$. vermiculophylla could similarly be due to an increased level of chemical defenses. This low palatability to one of the main grazers in invaded habitats could partly explain the invasion success of G. vermiculophylla. However, numerous other traits also cannot be excluded as potential factors of invasion success, as G. vermiculophylla can survive and spread under a wide range of abiotic conditions and is also able to survive extensive periods of desiccation and burial (Yokoya et al. 1999, Nyberg 2007, Thomsen \& McGlathery 2007, Weinberger et al. 2008, Nyberg \& Wallentinus 2009, Nejrup \& Pedersen 2012).

The variation of palatability within native populations of Gracilaria vermiculophylla is high, but overall Littorina brevicula and L. littorea found the same populations most palatable. The consumption of 2 native populations (Daecheon and Donghae, South Korea) by both snails was similar to that of invasive populations, while seaweeds from Odo
(South Korea) were of low palatability to L. brevicula only. Of all the native populations included in the present study, the Donghae population is genetically most similar to invasive populations (Kim et al. 2010), and genetic data hint at the Korean East Sea/Sea of Japan being the donor region for all invasive G. vermiculophylla populations (Kim et al. 2010). In this light, it is interesting that both populations from the Korean East Sea/Sea of Japan (Donghae and Odo) included in the present study were also among those native populations that have been fed on least. Possibly, low palatability is more widely spread among populations in the Korean East Sea/Sea of Japan; such pre-adapted genotypes were introduced into new habitats, and in their new environment they could settle and spread, as they were not controlled by grazers. Such a selective introduction of specific pre-adapted genotypes was also assumed for the South African ragwort Senecio inaequidens (Bossdorf et al. 2008).

\section{CONCLUSIONS}

Both Littorina brevicula and L. littorea consumed significantly higher amounts of native than of invasive Gracilaria vermiculophylla. The low palatability to $L$. littorea could thus be one reason for the invasion success of the seaweed. Furthermore, the results of our study show that it can be of great importance to compare more than only one native and one nonnative population of a species to understand the mechanisms underlying an invasion process. G. vermiculophylla populations originating from different ecoprovinces exhibit a high variability, especially within the native populations. A simple comparison of populations from the Baltic Sea and Qingdao might have led to the assumption that native populations are in general more palatable than non-native populations. However, consumption rates of G. vermiculophylla from some Korean populations were just as low as those of invasive populations. Therefore, we conclude that the invasion success of this species might have been facilitated by the introduction of herbivory-resistant genotypes.

Acknowledgements. Funding for this study was granted by the German Ministry of Education and Research (BMBF) through the Sino-German Initiative on Marine Sciences to M.H., by the Marine Biotechnology Grant from the Korean Ministry of Transport, Land, and Maritime Affairs to S.M.B., and by the State Agency for Agriculture, Environment, and Rural Areas (LLUR) of Schleswig-Holstein to F.W. We greatly appreciate the comments and suggestions on the manuscript by 3 anonymous referees. We thank the Institute 
of Clinical Molecular Biology in Kiel for providing Sanger sequencing as supported in part by the DFG (German Research Foundation) Cluster of Excellence 'Inflammation at Interfaces' and 'Future Ocean'. We thank the technicians S. Greve and S. Arndt for technical support.

\section{LITERATURE CITED}

Bellorin AM, Oliveira MC, Oliveira EC (2004) Gracilaria vermiculophylla: a western Pacific species of Gracilariaceae (Rhodophyta) first recorded from the eastern Pacific. Phycol Res 52:69-79

Blossey B, Notzold R (1995) Evolution of increased competitive ability in invasive nonindigenous plants: a hypothesis. J Ecol 83:887-889

Bossdorf O, Lipowsky A, Prati D (2008) Selection of preadapted populations allowed Senecio inaequidens to invade Central Europe. Divers Distrib 14:676-685

> Cacabelos E, Olabarria C, Incera M, Troncoso JS (2010) Do grazers prefer invasive seaweeds? J Exp Mar Biol Ecol 393:182-187

> Callaway RM, Ridenour WM (2004) Novel weapons: invasive success and the evolution of increased competitive ability. Front Ecol Environ 2:436-443

Cappuccino N, Arnason JT (2006) Novel chemistry of invasive exotic plants. Biol Lett 2:189-193

> Cappuccino N, Carpenter D (2005) Invasive exotic plants suffer less herbivory than non-invasive exotic plants. Biol Lett 1:435-438

> Diaz ER, Kraufvelin P, Erlandsson J (2012) Combining gut fluorescence technique and spatial analysis to determine Littorina littorea grazing dynamics in nutrient-enriched and nutrient-unenriched littoral mesocosms. Mar Biol 159:837-852

- Enge S, Nylund GM, Harder T, Pavia H (2012) An exotic chemical weapon explains low herbivore damage in an invasive alga. Ecology 93:2736-2745

Engelen AH, Henriques N, Monteiro C, Santos R (2011) Mesograzers prefer mostly native seaweeds over the invasive brown seaweed Sargassum muticum. Hydrobiologia 669:157-165

> Forslund H, Wikström SA, Pavia H (2010) Higher resistance to herbivory in introduced compared to native populations of a seaweed. Oecologia 164:833-840

> Freshwater DW, Montgomery F, Greene JK, Hamner RM, Williams M, Whitfield PE (2006) Distribution and identification of an invasive Gracilaria species that is hampering commercial fishing operations in Southeastern North Carolina, USA. Biol Invasions 8:631-637

Guillemin ML, Akki SA, Givernaud T, Mouradi A, Valero M, Destombe C (2008) Molecular characterisation and development of rapid molecular methods to identify species of Gracilariaceae from the Atlantic coast of Morocco. Aquat Bot 89:324-330

Hay ME, Steinberg PD (1992) The chemical ecology of plant-herbivore interactions in marine versus terrestrial communities. In: Rosenthal GA, Berenbaum MR (eds) Herbivores: their interactions with secondary plant metabolites. II. Evolutionary and ecological processes. Academic Press, San Diego, CA, p 371-413

Hierro JL, Maron JL, Callaway RM (2005) A biogeographical approach to plant invasions: the importance of studying exotics in their introduced and native range. $\mathrm{J}$ Ecol 93:5-15
Joshi J, Vrieling K (2005) The enemy release and EICA hypothesis revisited: incorporating the fundamental difference between specialist and generalist herbivores. Ecol Lett 8:704-714

> Keane RM, Crawley MJ (2002) Exotic plant invasions and the enemy release hypothesis. Trends Ecol Evol 17: 164-170

> Kim SJ, Rodríguez-Lanetty M, Song JI (2003) Genetic population structure of Littorina brevicula around Korean waters. Hydrobiologia 505:41-48

Kim SY, Weinberger F, Boo SM (2010) Genetic data hint at a common donor region for invasive Atlantic and Pacific populations of Gracilaria vermiculophylla (Gracilariales, Rhodophyta). J Phycol 46:1346-1349

Kraufvelin P, Salovius S, Christie H, Moy FE, Karez R, Pedersen MF (2006) Eutrophication-induced changes in benthic algae affect the behaviour and fitness of the marine amphipod Gammarus locusta. Aquat Bot 84:199-209

> Mattson WJJ (1980) Herbivory in relation to plant nitrogen content. Annu Rev Ecol Syst 11:119-161

Molis M, Körner J, Ko YW, Kim JH (2008) Specificity of inducible seaweed anti-herbivory defences depends on identity of macroalgae and herbivores. Mar Ecol Prog Ser 354:97-105

> Monteiro CA, Engelen AH, Santos ROP (2009) Macro- and mesoherbivores prefer native seaweeds over the invasive brown seaweed Sargassum muticum: a potential regulating role on invasions. Mar Biol 156:2505-2515

Morton B (1990) The rocky shore ecology of Qingdao, Shandong Province, People's Republic of China. Asian Mar Biol 7:167-187

> Nejrup LB, Pedersen MF (2010) Growth and biomass development of the introduced red alga Gracilaria vermiculophylla is unaffected by nutrient limitation and grazing. Aquat Biol 10:249-259

Nejrup LB, Pedersen MF (2012) The effect of temporal variability in salinity on the invasive red alga Gracilaria vermiculophylla. Eur J Phycol 47:254-263

Nejrup LB, Pedersen MF, Vinzent J (2012) Grazer avoidance may explain the invasiveness of the red alga Gracilaria vermiculophylla in Scandinavian waters. Mar Biol 159: 1703-1712

Nyberg CD (2007) Introduced marine macroalgae and habitat modifiers - their ecological role and significant attributes. PhD dissertation, Göteborg University

Nyberg CD, Wallentinus I (2005) Can species traits be used to predict marine macroalgal introductions? Biol Invasions 7:265-279

Nyberg CD, Wallentinus I (2009) Long-term survival of an introduced red alga in adverse conditions. Mar Biol Res 5:304-308

Nylund GM, Weinberger F, Rempt M, Pohnert G (2011) Metabolomic assessment of induced and activated chemical defence in the invasive red alga Gracilaria vermiculophylla. PLoS ONE 6:e29359

> Pinon-Gimate A, Serviere-Zaragoza E, Ochoa-Izaguirre MJ, Paez-Osuna F (2008) Species composition and seasonal changes in macroalgal blooms in lagoons along the southeastern Gulf of California. Bot Mar 51:112-123

> Rempt M, Weinberger F, Grosser K, Pohnert G (2012) Conserved and species-specific oxylipin pathways in the wound-activated chemical defense of the noninvasive red alga Gracilaria chilensis and the invasive Gracilaria vermiculophylla. Beilstein J Org Chem 8: 283-289 
Saunders GW (2009) Routine DNA barcoding of Canadian Gracilariales (Rhodophyta) reveals the invasive species Gracilaria vermiculophylla in British Columbia. Mol Ecol Resour 9:140-150

Schories D, Selig U (2006) Die Bedeutung eingeschleppter Arten (alien species) für die Europäische Wasserrahmenrichtlinie am Beispiel der Ostsee. Rostock Meeresbiol Beitr 15:147-158

Sfriso A, Maistro S, Andreoli C, Moro I (2010) First record of Gracilaria vermiculophylla (Gracilariales, Rhodophyta) in the Po Delta Lagoons, Mediterranean Sea (Italy). J Phycol 46:1024-1027

Son MH, Hong SY (1998) Reproduction of Littorina brevicula in Korean waters. Mar Ecol Prog Ser 172:215-223

Spalding MD, Fox HE, Allen GR, Davidson N and others (2007) Marine ecoregions of the world: a bioregionalization of coastal and shelf areas. Bioscience 57:573-583

Thomsen MS, McGlathery KJ (2007) Stress tolerance of the invasive macroalgae Codium fragile and Gracilaria vermiculophylla in a soft-bottom turbid lagoon. Biol Invasions 9:499-513

Thomsen MS, McGlathery KJ, Tyler AC (2006) Macroalgal distribution patterns in a shallow, soft-bottom lagoon, with emphasis on the nonnative Gracilaria vermiculophylla and Codium fragile. Estuar Coast 29:465-473

Thomsen MS, Staehr PA, Nyberg CD, Schwærter S, KrauseJensen D, Silliman BR (2007a) Gracilaria vermiculophylla (Ohmi) Papenfuss, 1967 (Rhodophyta, Gracilariaceae) in northern Europe, with emphasis on Danish conditions, and what to expect in the future. Aquat Invasions 2:83-94

Thomsen MS, Wernberg T, Stææhr P, Krause-Jensen D, Risgaard-Petersen N, Silliman BR (2007b) Alien macroalgae

Editorial responsibility: Morten Pedersen, Roskilde, Denmark in Denmark - a broad-scale national perspective. Mar Biol Res 3:61-72

Underwood AJ (1997) Experiments in ecology: their logical design and interpretation using analysis of variance. Cambridge University Press, Cambridge

Van Alstyne KL, Pelletreau KN, Kirby A (2009) Nutritional preferences override chemical defenses in determining food choice by a generalist herbivore, Littorina sitkana. J Exp Mar Biol Ecol 379:85-91

- Watson DC, Norton TA (1985) Dietary preferences of the common periwinkle, Littorina littorea (L.). J Exp Mar Biol Ecol 88:193-211

Weinberger F, Buchholz B, Karez R, Wahl M (2008) The invasive red alga Gracilaria vermiculophylla in the Baltic Sea: adaptation to brackish water may compensate for light limitation. Aquat Biol 3:251-264

> Weinberger F, Lion U, Delage L, Kloareg B and others (2011) Up-regulation of lipoxygenase, phospholipase, and oxylipin-production in the induced chemical defense of the red alga Gracilaria chilensis against epiphytes. J Chem Ecol 37:677-686

Wikström SA, Steinarsdottir MB, Kautsky L, Pavia H (2006) Increased chemical resistance explains low herbivore colonization of introduced seaweed. Oecologia 148: 593-601

Williams JL, Auge H, Maron JL (2008) Different gardens, different results: native and introduced populations exhibit contrasting phenotypes across common gardens. Oecologia 157:239-248

Yokoya NS, Kakita H, Obika H, Kitamura T (1999) Effects of environmental factors and plant growth regulators on growth of the red alga Gracilaria vermiculophylla from Shikoku Island, Japan. Hydrobiologia 398/399:339-347

Submitted: October 15, 2012; Accepted: April 3, 2013 Proofs received from author(s): July 1, 2013 